Academic Platform Journal of Engineering and Science

journal homepage: https://dergipark.org.tr/tr/pub/apjes

\title{
On the Energy Absorption Capability of Metallic Tubes Subjected to the Radial Wall Crushing Process
}

\author{
*1YYaşar Kahraman \\ ${ }^{1}$ Sakarya University, Faculty of Engineering, Department of Mechanical Engineering, kahraman@ sakarya.edu.tr, \\ Research Paper \\ Arrival Date: 06.01.2021 \\ Accepted Date: 01.03.2021
}

\begin{abstract}
Metallic tubes, under axial loading, are frequently preferred in many different industries due to their high energy absorption efficiency. The studies to increase the energy absorption capacity (EAC) of these structures are still up to date. In this study, the deformation behavior and EAC of regionally pre-deformed identical aluminum and steel tubes under axial loading were investigated experimentally. An increase of regional strength in tubes was obtained by the radial wall crushing (RWC) process. The RWC process is carried out radially by crushing desired regions of metallic tubes from the outside using a specially designed device. Strengthening (hardening) occurs in the pre-deformed regions and as a result, the EAC of the metallic tubes can be increased. It is also noteworthy that the increase in absorbed energy is provided without reinforcement materials. It was seen from the experimental results that the energy absorption value of aluminum and steel tubes were increased by approximately $23 \%$ and $33 \%$, respectively by the RWC process. In addition to energy increases, the folding beginning of the metallic tubes can also be directed by using the RWC process.
\end{abstract}

Keywords: radial wall crushing, aluminum, steel, tubular, energy absorption capability

\section{INTRODUCTION}

Energy-absorbing structures are commonly used to minimize injuries to drivers and passengers and also used to protect the main structures from damages. Accordingly, metallic tubes are frequently used in the aviation and automotive industries, where a higher ratio of strength to lightness is desired. Although the studies on metallic tubes are dated to the second half of the 20th century, they are still up to date. In this context, it is possible to reach many studies [1]c[5] on the deformation behavior and energy absorption capability of metallic tubes. Alexander [1] examined the deformation of steel tubes and showed that the absorbed energy by the metallic tubular structures is directly related to the geometric properties of the tube structure. It has been observed from the study that the main factor in the absorbed energy is the tube wall thickness [2].

To increase the absorbed energy values, many researchers used different types of foams [6]-[9] and fibers [10]-[14] as a reinforcement method. In these studies, it has been reported that using reinforcement materials resulted in increasing the absorbed energy value. However, the weight of the tubular structures was also increased which is an undesirable situation for the energy efficiency parameter of specific energy absorption (SEA). The SEA is one of the most important crashworthiness parameters which is defined as the absorbed energy per unit weight [15]. Accordingly, if the increase in weight is higher compare to the increase in absorbed energy, reinforcement materials using would be useless. It is noted in some of the studies mentioned above the SEA value was obtained lower than the non-reinforced structure. In this context, increasing the SEA value appears as the main target in the studies on tubular structures.

In this study, the absorbed energy of metallic tubes is tried to be increased. Accordingly, the radial wall crushing (RWC) process which contains none of the reinforcement materials was applied to the metallic tubes. Related to the increase in absorbed energy due to the RWC process, the SEA values of tubes are expected to increase as well.

\section{MATERIAL AND METHODS}

\subsection{Material Properties and Experimental Set-up}

In the experimental studies, 6063-T5 series aluminum alloy and seamless steel tubes with $58 \mathrm{~mm}$ diameter, $1.5 \mathrm{~mm}$ wall thickness were used. Two different lengths as $34 \mathrm{~mm}$ and $100 \mathrm{~mm}$ for aluminum and $100 \mathrm{~mm}$ for steel tubes were selected and used in the experiments. The short-length aluminum tubes were used to examine that how the RWC process affects the deformation behavior and the energy absorption of tubes. After that, the long-length aluminum

${ }^{* 1}$ Corresponding author: Sakarya University, Faculty of Engineering, Department of Mechanical Engineering, kahraman@ sakarya.edu.tr 
and steel tubes were used for multiple RWC processes to obtain the most sufficient design.

Although aluminum and steel pipes are manufactured by extrusion, there may be differences in wall thickness on cross-section and this causes a wide scattering in the experimental results. For this reason, to obtain homogeneous wall thickness, CNC milling was operated from inside and outside of the pipes (Figure 1). Before CNC milling, steel pipes were heat-treated to increase ductility. Thus, damages that could occur during folding of the tube under axial loading were prevented. To determine the mechanical properties of the tube structure, a tensile test was carried out on an Instron tensile testing device with a capacity of $5 \mathrm{kN}$. A video extensometer has been used for more precise measurements. The mechanical properties of the tubular structure are given in Table 1 . In the axial crushing tests of all tubes with and without an RWC process, a $250 \mathrm{kN}$ capacity, hydraulic driven press was used. The experiments were carried out at a speed of $1 \mathrm{~mm} / \mathrm{s}$. The forcedisplacement data of the experiments were transferred to the computer as approximately 6 data/s. Also, all experiments were recorded with the help of a camera.

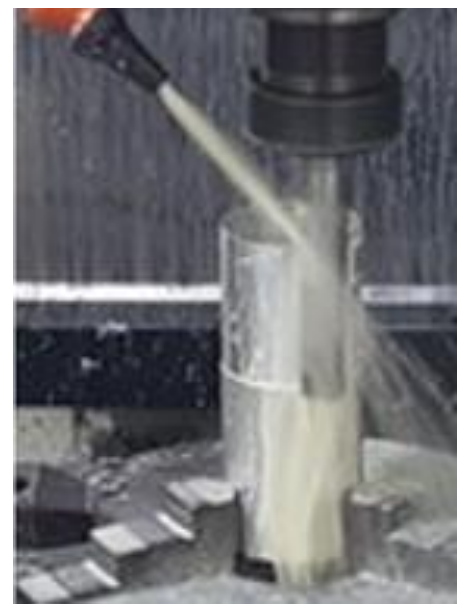

Figure 1. CNC milling operation of aluminum and steel pipe

Table 1. Mechanical properties of aluminum and steel tubular structures

\begin{tabular}{ccccc}
\hline & $\begin{array}{c}\text { Elasticity } \\
\text { modulus } \\
(\mathrm{GPa})\end{array}$ & $\begin{array}{c}\text { Yield } \\
\text { strength } \\
(\mathrm{MPa})\end{array}$ & $\begin{array}{c}\text { Tensile } \\
\text { strength } \\
(\mathrm{MPa})\end{array}$ & $\begin{array}{c}\text { Poisson } \\
\text { ratio }\end{array}$ \\
\hline $\begin{array}{c}\text { Aluminum } \\
\text { 6063-T5 } \\
\text { Steel }\end{array}$ & 69 & 188 & 212 & 0.33 \\
St-52 & 200 & 325 & 560 & 0.3 \\
\hline
\end{tabular}

\subsection{Radial Wall Crushing (RWC) Process}

The RWC process, which is based on strain hardening by applying regional pre-deformation to the tube wall, increases the energy absorption capacity of the metallic tube. Wall crushing is carried out using the device given in Figure 2. The process starts with placing the tube on the shaft then the idler rotating disk is pressed into the tube wall at the desired rate. Finally, the process completes after a full rotation of the tube around itself. A multiple wall crushed aluminum tube and its schematic view are given in Figure 3. From the figure, $\mathrm{w}$ and $\lambda$ are related to the wall crushed region and free folding length, respectively. With this process, the absorbed energy value of the tube structure under axial loading is tried to be increased without using any reinforcement material.

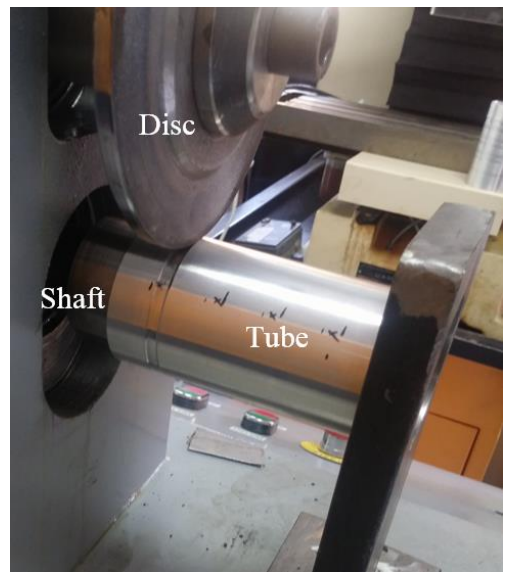

Figure 2. The radial wall crushing (RWC) device
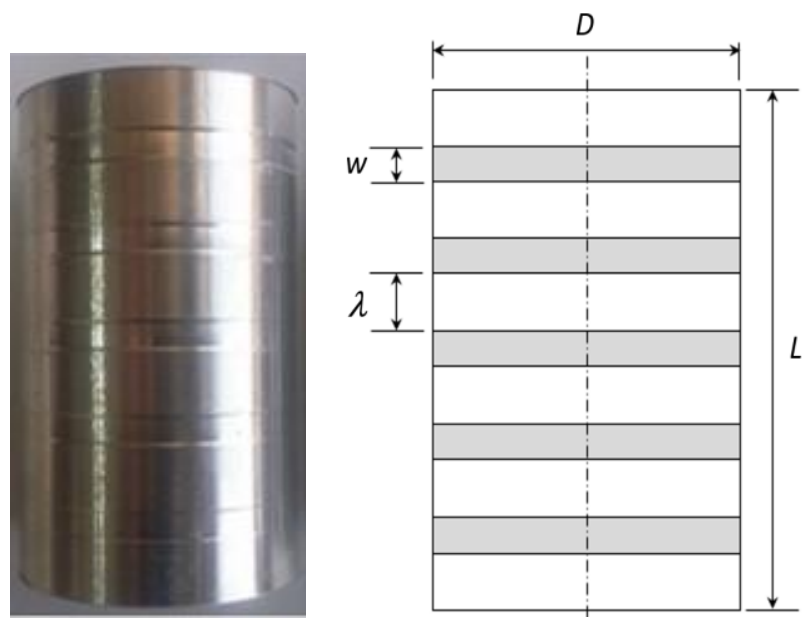

Figure 3. A multiple wall crushed aluminum tube and its schematic view

\section{RESULTS AND DISCUSSION}

In this section, the experimental results of the base and radially wall crushed tube specimens have been examined. The hardness of the tube wall changes due to predeformation related to the RWC process. As given in Figure 4, the hardness values of the aluminum and steel base tubes are $78 \mathrm{HV}$ and $135 \mathrm{HV}$ and they increase to $85 \mathrm{HV}$ and 163 $\mathrm{HV}$ respectively on the crushed region. The increase in hardness causes an increase in the strength of this region, it also causes a decrease in the ductility (plastic deformation ability) of the tube. 


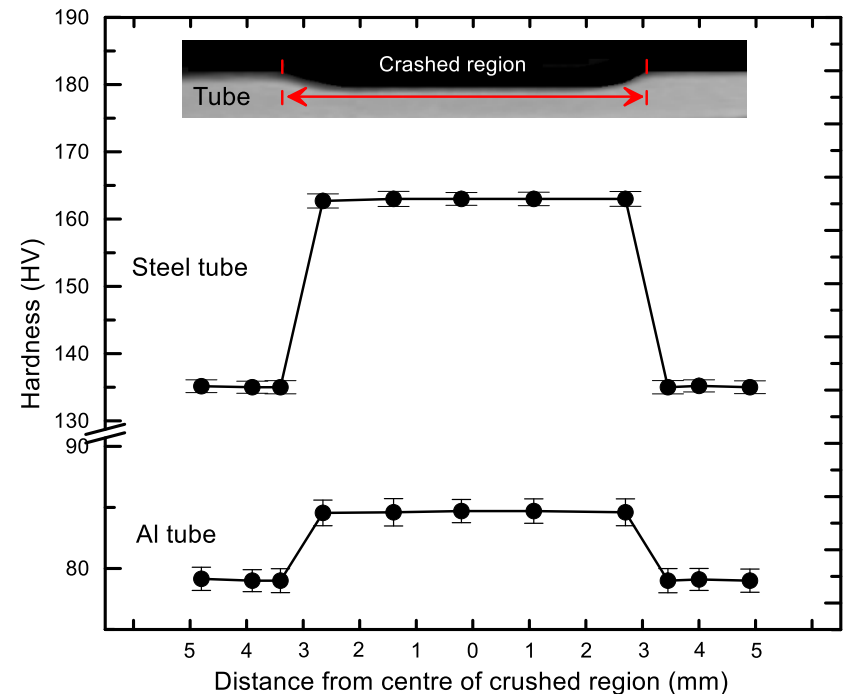

Figure 4. Variation of tube wall hardness after the RWC process

To see the effect of the RWC process on the deformation behavior of the tube, the process was first applied to the short tubes with free folding lengths $(\lambda)$ of $10 \mathrm{~mm}$ and $20 \mathrm{~mm}$. The force-displacement curves and deformation behaviors of these specimens are given in Figure 5 and Figure 6. It is seen from the figure that the RWC process increases the first peak force compared to the base tube. Besides, the lower force values, corresponding to the completion of the first fold, shifted to the right (Figure 5). It is understood that the highest absorbed energy was obtained at the end of the first folding of the specimen with $\lambda$ of $10 \mathrm{~mm}$. It is seen from Figure 6 that the deformation began close to the upper end in the base tube while it was between the rolled regions by the RWC process. In the tube with $\lambda$ of $10 \mathrm{~mm}$, deformation started in the middle of the wall crushed regions and continued in this way. In the $\lambda$ of $20 \mathrm{~mm}$ specimen, the fold again occurred only slightly under the upper rolled region.

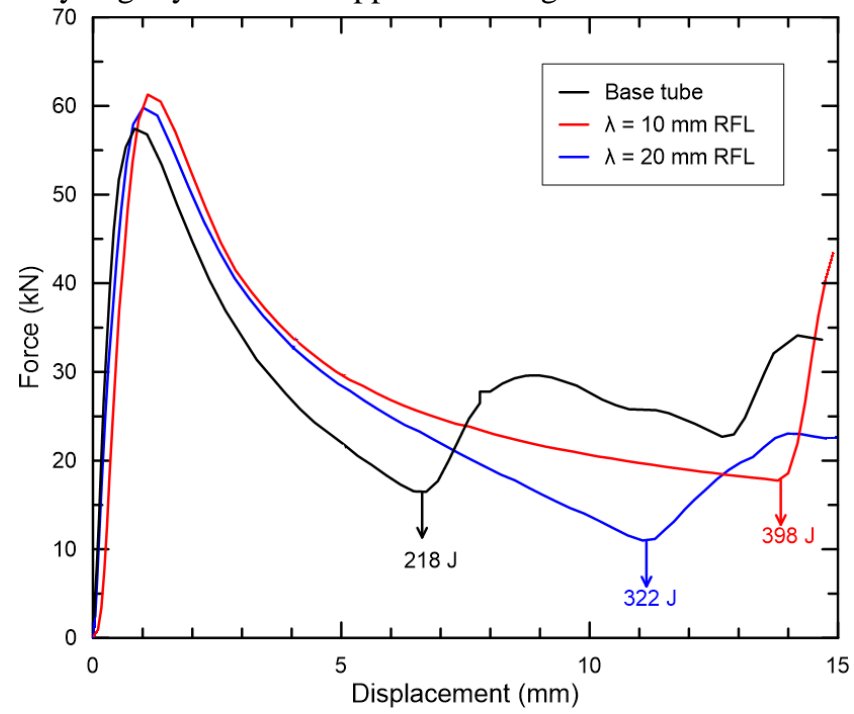

Figure 5. The force-displacement curves of the base and the RWC applied tubes
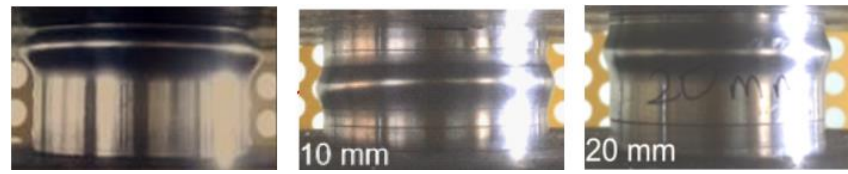

Figure 6. The deformation in the base and the RWC applied tubes

For long tubes different $\lambda$ values are used as variable parameters in RWC. In this context, the force-displacement curves of the tubes with the $\lambda$ of $10 \mathrm{~mm}, 12 \mathrm{~mm}, 16 \mathrm{~mm}$, and $20 \mathrm{~mm}$ are given in Figure 7. From the figure, it is seen that the upper force values approach the first peak force with decreasing of the $\lambda$ values. $\lambda=12 \mathrm{~mm}$ and $\lambda=16 \mathrm{~mm}$ curves lie between $10 \mathrm{~mm}$ and $20 \mathrm{~mm}$ curves as expected. When the graphic is examined, it is seen that the RWC process changes the characteristic of the force curve, and thus the energy value is increased. This situation occurs as a result of i) restriction of the length of folding by the RWC process, ii) inclusion of rolled regions with higher strength into the folding process. The absorbed energy values increased with decreasing $\lambda$ values and the highest energy was obtained in the specimen with $\lambda$ of $10 \mathrm{~mm}$ as $2353 \mathrm{~J}$ which is $23 \%$ higher than the base tube. This is the most efficient value for the RWC process.

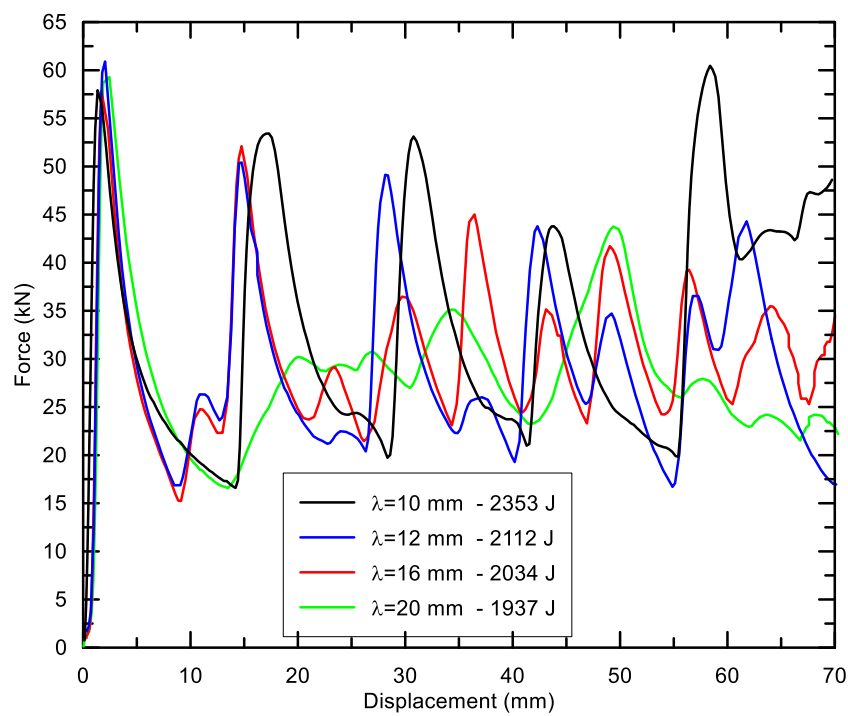

Figure 7. Force-displacement curves of aluminum tubes with different $\lambda$ values

Some other processes such as grooving the tubes were studied in the literature [16]-[18] to change the tube wall stability efficiently. In these studies, tube wall stability was changed locally by cutting wide grooves from the outer surface of the metallic tubes. However, these cutting operations caused locally decreased regions on the tube wall. In contrast to these studies, locally strengthening was obtained by the RWC process in this study. In addition, it was reported by Daneshi and Hosseinipour [19] that the deformation beginning and the characteristic of the forcedisplacement curve could be control by the grooving process. It was concluded as an important point from these studies that there was not an increase in absorbed energy compared 
to non-grooved tubes. Another study on axially compressed grooved square tubes by Lee [20] was showed similar results. In contrast to these studies on grooving, to be able to change the folding start and sequence of the tube and to increase the absorbed energy without machining show the importance of this study.

The axial crushing results of the steel tubes are given in Figure 8. It is seen that after the RWC process, the first peak force increased by almost $25 \%$ compared to the base tube. Also, the absorbed energy was obtained as $6775 \mathrm{~J}$ which is $37 \%$ higher than the steel base tube. These results are important to show that the RWC process becomes more effective if it is applied to materials with higher strain hardening ability. The RWC process also increases the average force value, which can be defined as the ramp effect. Also, the process allows the folding initiates far from the ends of the tube for the RWC applied tube (Figure 9). This situation has critical importance in the aspect of being able to redirect the deformation beginning.

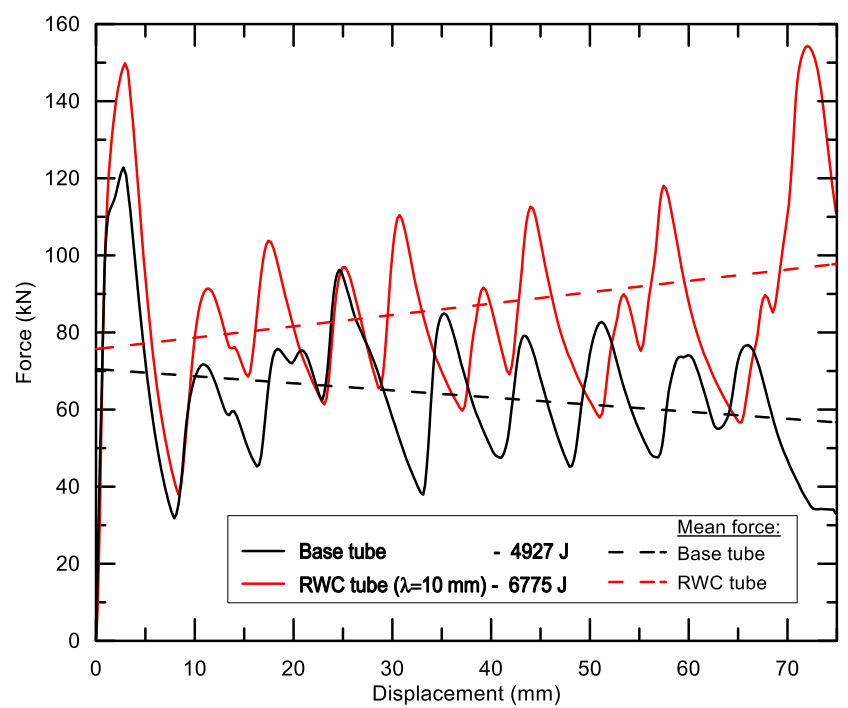

Figure 8. Force-displacement curves of the steel base and RWC applied tubes
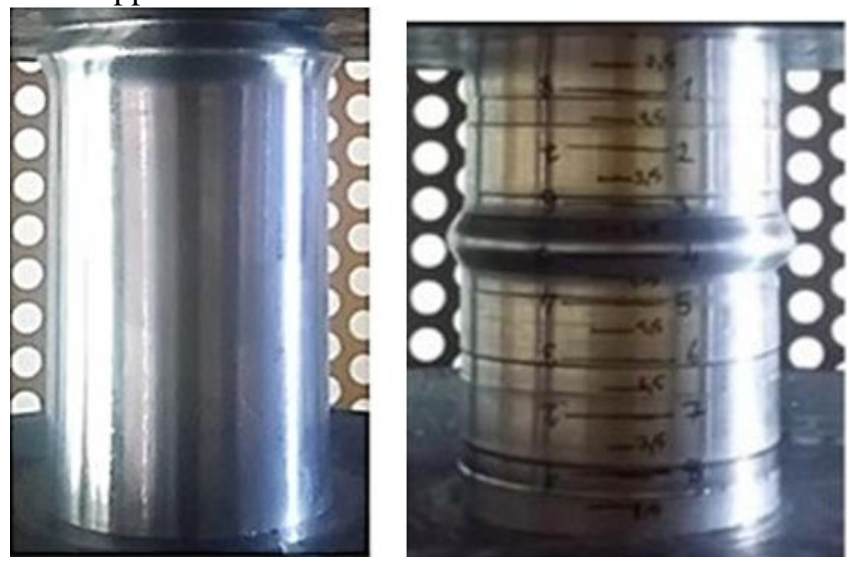

Figure 9. The difference of deformation beginning of base and RWC applied tubes

As a result of the RWC process, the absorbed energy of aluminum and steel tubes increased by $23 \%$ and $33 \%$ compared to the non-reinforced tube, respectively. This improvement in absorbed energy is also reflected in the SEA at the same ratio because there is not any increase in the weight of the tubes in the RWC process. Even some studies [7]-[15] reported an enhancement in the SEA of the tubular structures in the literature, it is concluded that reinforcement materials such as foams, fibers, etc were used in these studies. Providing an increase in both absorbed energy and the SEA without using any reinforcing element (without any increase in the weight of the tubular structure) also reveals the importance of RWC. Considering that improving the SEA is the most important achievement according to the crashworthiness of the energy-absorbing structures, it is possible to say that the RWC process is useful. It is also important that there is no milling or machining process in the RWC compare to similar studies [17]-[19] which could be caused decreasing in the tube wall stability. Finally, by using samples produced from materials with good hardening ability the RWC process will be contributed to the absorbed energy and the SEA at a higher rate.

Author contributions: Concept - Y.K.; Data Collection \&/or Processing - Y.K.; Literature Search - Y.K.; Writing Y.K.

Conflict of Interest: No conflict of interest was declared by the author.

Financial Disclosure: The authors declared that this study has received no financial support.

\section{REFERENCES (IEEE STYLE)}

[1] J. M. Alexander, "An approximate analysis of collapse of thin-walled cylindrical shells under axial loading," Q. J. Mech. Applied Math., vol. 13, pp. 10-15, 1960.

[2] D. Al Galib and A. Limam, "Experimental and numerical investigation of static and dynamic axial crushing of circular aluminum tubes," Thin Walled Struc., vol. 42, pp. 1103-1137, 2004.

[3] R. Baleh and A. Abdul-Latif, "Quasi-static biaxial plastic buckling of tubular structures used as an energy absorber," Transactions of the ASME, vol. 74, pp. 628-635, 2007.

[4] Z. Tang, S. Liu, and Z. Zhang, "Analysis of energy absroption chareacteristics of cylindrical multi-cell columns," Thin Walled Struc., vol. 62, pp. 75-84, 2013.

[5] M. M. Yalçın, O. H. Mete, and K. Genel, "Axial crushing behavior of circular aluminum tubes," Materials Testing, vol. 61, no. 8, pp. 749-754, Aug. 2019.

[6] A. Baroutaji, M. D. Gilchrist, D. Smyth, and A. G. Olabi, "Crush analysis and multi-objective optimization design for circular tube under quasi-static lateral loading," Thin Walled Struc., vol. 86, pp. 121-131, 2015.

[7] S. R. Guillow, G. Lu, and R. H. Grzebieta, "Quasistatic axial compression of thin-walled circular aluminium tubes,” Int. J. Mech. Sci., vol. 43, pp. 2103-2123, 2001.

[8] M. Langseth, O. S. Hopperstad, and A. G. Hanssen, "Crash behaviour of thin-walled aluminium members," Thin Walled Struc., vol. 32, pp. 127-150, 1998. 
[9] M. M. Yalçın and K. Genel, "On the axial deformation characteristic of PVC foam-filled circular aluminium tube: Effect of radially-graded foam filling," Thin Walled Struc., vol. 144, 2019.

[10] M. R. Bambach and M. Elchalakani, "Plastic mechanism analysis of steel SHS strengthened with CFRP under large axial deformation," Thin Walled Struc., vol. 45, pp. 159-170, 2007.

[11] G. D. Hatzigeorgiou and D. E. Beskos, "Minimum cost design of fibre-reinforced concrete-filled steel tubular columns," J Constructional Steel Res., vol. 61, pp. 167-182, 2005.

[12] A. Henningsgaard and C. Yanchar, "Carbon fiber reinforced steel spaceframe techniques," SAE Tech. Paper Series, no. 724, pp. 1-10, 1998.

[13] H. C. Kim, D. K. Shin, J. J. Lee, and J. B. Kwon, "Crashworthiness of aluminum / CFRP square hollow section beam under axial impact loading for crash box application," Comp. Struc., vol. 112, pp. 1-10, 2014.

[14] M. M. Yalçın and K. Genel, "On the axial crush performance of PVC foam-filled aluminum/CFRP hybrid circular tube," Sakarya University J. Sci., vol. 23, no. 6, pp. 1154-1162, 2019.

[15] T. Y. Reddy, R. J. Wall, M. Engineering, P. O. Box, and M. M. Iqd, "Axial compression of foam-filled thin- walled circular tubes,” Int. J. Impact Eng., vol. 7, no. 2, pp. 151-166, 1988.

[16] S. Salehghaffari, M. Tajdari, M. Panahi, and F. Mokhtarnezhad, "Attempts to improve energy absorption characteristics of circular metal tubes subjected to axial loading," Thin Walled Struc., vol. 48, no. 6, pp. 379-390, 2010.

[17] F. Mokhtarnezhad, S Salehghaffari, M. Tajdari, "Improving the crashworthiness characteristics of cylindrical tubes subjected to axial compression by cutting wide grooves from their outer surface," Int. J. Crashworthiness, vol. 14, no. 6, pp. $601-611,2009$.

[18] A. Darvizeh, M. Darvizeh, R. Ansari, A. Meshkinzar, "Effect of low density, low strength polyurethane foam on the energy absorption characteristics of circumferentially grooved thick-walled circular tubes," Thin Walled Struc., vol. 71, pp. 81-90, 2013.

[19] G. H. Daneshi, S. J. Hosseinipour, "Elastic-plastic theory for initial buckling load of thin-walled grooved tubes under axial compression". J. Mater. Process. Tech., vol. 125, pp. $826-832,2002$.

[20] S. Lee, C. Hahn, M. Rhee, J. E. Oh, "Effect of triggering on the energy absorption capacity of axially compressed aluminum tubes," Mater. Des., vol. 20, no. 1, pp. 31-40, 1999. 